\title{
Corrigendum
}

\section{From pack animals to polo: donkeys from the ninth-century Tang tomb of an elite lady in Xi'an, China-CORRIGENDUM}

Songmei Hu, Yaowu Hu, Junkai Yang, Miaomiao Yang, Pianpian Wei, Yemao Hou \& Fiona B. Marshall

Published by Cambridge University Press, 17 March 2020

In this article, on pages 458, 468 and 472, it states that Cui Shi was the wife of Bao Gao (高寶). This is incorrect. Cui Shi was the wife of Bao Zhou (周寶), the governor of the Jingyuan (涇源) and Zhenghai (鎮海) areas during the late Tang Dynasty.

\section{Full citation}

Hu, S., Y. Hu, J. Yang, M. Yang, P. Wei, Y. Hou \& F.B. Marshall. 2020. From pack animals to polo: donkeys from the ninth-century Tang tomb of an elite lady in Xi'an, China. Antiquity 94: 455-72. https://doi.org/10.15184/aqy.2020.6

(C) Antiquity Publications Ltd, 2020 